\title{
ESCAPE ROOM: UMA PROPOSTA DE JOGO PEDAGÓGICO NO ESCOPO DA EDUCAÇ̃̃O TÉCNICA DE NÍVEL MÉDIO ${ }^{1}$
}

\author{
Guilherme da Silva Lima² \\ Ederson dos Santos Ramalho \\ Juliana Ventura de Souza Fernandes \\ Edio da Costa Junior
}

\begin{abstract}
RESUMO
Este artigo elabora e discute as etapas de construção de um jogo pedagógico original para aplicações em turmas de cursos técnicos em eletroeletrônica integrado ao ensino médio. Mostra-se que com pequenas modificações, o jogo proposto pode ser desenvolvido em turmas de outros cursos técnicos, bem como em turmas do ensino médio convencional. As adequações necessárias residem na mudança de foco das discussões propostas inicialmente no jogo. É notório que atualmente, diversos jogos pedagógicos são aplicados com êxito no escopo da educação de nível básico e de nível superior, mas o jogo proposto neste artigo se baseia em uma alternativa ainda pouco explorada: o jogo Escape Room. Observando a baixa disseminação desse jogo entre os educadores, torna-se necessário a descrição pormenorizada do itinerário trilhado para o seu desenvolvimento para possibilitar uma eficaz reprodutibilidade. $O$ jogo proposto é mais uma metodologia de ensino que pode ser utilizada por professores que almejam diversificar o processo de ensino e aprendizagem, visto que após uma leve adaptação do jogo para a realidade de sua sala de aula, a atividade lúdica estará pronta, o que otimiza o tempo para o planejamento da atividade de ensino. Além disso, a interdisciplinaridade alcançada pelos desafios do jogo permite uma ampla discussão de conteúdos transversais, o que enriquece a aprendizagem de alunos e professores.
\end{abstract}

Palavras-chave: Escape Room. Jogos pedagógicos. Abordagem interdisciplinar.

\section{ESCAPE ROOM: A PROPOSAL OF PEDAGOGICAL GAME WITHIN THE SCOPE OF BASIC TECHNICAL EDUCATION}

\begin{abstract}
This paper elaborates and discusses the construction steps of an original pedagogical game for applications in classes of technical courses in electronics integrated to high school. It is shown that with small modifications, the proposed game can be developed in classes of other technical courses, as well as in classes of conventional high school. The necessary adjustments lie in changing the focus of the discussions initially proposed in the game. It is well known that currently, several pedagogical games are successfully applied in high school and university

\footnotetext{
${ }^{1}$ Como citar este artigo:

LIMA, G. da S. et al. Escape room: uma proposta de jogo pedagógico no escopo da educação técnica de nível médio. ForScience, Formiga, v. 8, n. 2, e00851, jul./dez. 2020. DOI: 10.29069/forscience.2020v8n2.e851

${ }^{2}$ Autor para correspondência: Guilherme da Silva Lima, e-mail: guilherme.silva@ifmg.edu.br.
} 
education scope, but the game proposed in this paper is based on an alternative still little explored: the Escape Room game. Observing the low dissemination of this game among educators, it is necessary to describe in detail the itinerary followed for its development to enable an effective reproducibility. The proposed game is another teaching methodology that can be used by educators who aim to diversify the teaching and learning process, since after a slight adaptation of the game to the reality of their classroom, the play activity will be ready, which optimizes the time for planning the teaching activity. In addition, the interdisciplinarity achieved by the challenges of the game allows a wide discussion of transversal contents, which enriches the learning of students and teachers.

Keywords: Escape room. Pedagogical games. Interdisciplinary approach.

\section{INTRODUÇÃO}

Não são raros os relatos atuais de educadores que encaram turmas desmotivadas, desatentas e improdutivas, principalmente nas áreas das ciências exatas. Os métodos aplicados para a exposição dos conteúdos contribuem, muitas vezes, para o desinteresse das turmas (OLIVEIRA; OLIVEIRA, 2013). Esses fatores têm mantido os índices de letramento em ciências exatas em níveis baixos ao longo das últimas décadas no Brasil (FIALHO; MENDONÇA, 2020). A título de comparação, Fialho e Mendonça (2020) mostraram a pequena evolução média no letramento na área de ciências no período compreendido entre os anos de 2006 e 2015, o que colocou o Brasil na $52^{\circ}$ posição entre 57 países participantes do Programa Internacional de Avaliação de Alunos (PISA, do inglês Programme for International Student Assessment). Além disso, as metodologias de ensino e aprendizagem aplicadas em sala de aula não são diversificadas o suficiente para estarem adequadas para toda a turma (SCHMECK, 1988; KOLB; KOLB, 2005). Assim, as práticas conteudistas tradicionais não são capazes de abarcar toda a turma, fazendo com que os discentes não encontrem aplicabilidade imediata nos conteúdos puramente transmitidos em sala de aula. A falta de contextualização prática, o distanciamento do mundo em que os discentes vivem (FREIRE, 2013) e uma metodologia de ensino e aprendizagem inapropriada, podem tornar as salas de aula espaços com os quais os discentes não se identificam.

Conhecer os aspectos formativos que tornam os alunos únicos, bem como as características comuns das turmas é fundamental para que o docente seja capaz de dar significado à palavra dos discentes, fazendo com que eles se tornem sujeitos ativos no processo de ensino e aprendizagem (FREIRE, 2011, p. 105). Essa participação ativa tem se mostrado uma opção para manter as turmas interessadas pelas aulas e pelas discussões inerentes à sala de aula. As metodologias ativas de aprendizagem são dedicadas a tornarem os 
discentes sujeitos ativos no processo de ensino e aprendizagem (FOGARTY, 1998). Essas metodologias visam tornar os alunos mais proativos e criativos nos espaços educacionais. Para isso, utilizam atividades com um nível de complexidade que incentiva os alunos a tomarem decisões e avaliarem os resultados dessas atividades estimulantes (BACICH; MORAN, 2017). Uma metodologia ativa bastante difundida é a Aprendizagem Baseada em Problemas (ABP) que busca, a partir da proposição de um problema desafiador, que tem sentido real para os discentes, desenvolver os conteúdos de uma disciplina ou de um conjunto de disciplinas (FOGARTY, 1998). Romanatto (2012) considera a ABP como uma opção que não apresenta uma grande ruptura com as práticas conteudistas e, que, portanto tem menos rejeição pelos docentes tradicionalistas que optam por trabalhar na zona de conforto (BORDA; PENTEADO, 2001), mas que possibilita reflexões sobre o processo e a inversão da sequência didática propostas nos livros.

A utilização de jogos tem sido uma alternativa utilizada em diversos contextos para tornar os discentes agentes ativos do processo de ensino e aprendizagem. Em linhas gerais, todo jogo busca a imersão dos participantes em um espaço fora da realidade habitual, onde são necessárias habilidades temporais, espaciais e colaborativas entre os jogadores para se alcançar algum objetivo (TORI, 2010, p 185). Além disso, os jogos são ferramentas capazes de desenvolver uma nova forma de comunicação, criando uma cultura entre seus jogadores (HUIZINGA, 1996). Entender essa nova cultura e utilizá-la em favor da melhor prática pedagógica e educacional é um desafio ao desenvolvimento de jogos educativos.

Existem correntes pedagógicas que são favoráveis à utilização de jogos em espaços educacionais por acreditarem que são facilitadores no processo de aprendizagem, ao passo que existem correntes contrárias à utilização de jogos, por acreditarem que tornam superficiais a abordagem de conteúdos curriculares (LIMA, 2008, p 13). O pedagogo Frederico Froebel (1782-1852), idealizador do Jardim da Infância, e o psicólogo Edouard Claparède (1873-1940) reconheciam nos jogos um recurso pedagógico privilegiado. Por outro lado, Freinet (1960, p 169) diverge da ideia da utilização de jogos em espaços educacionais, entendendo que eles não são capazes de substituir o trabalho escolar que trazem maior significação para as atividades realizadas. Lima (2008, p 19) “defende que é possível a conciliação entre o jogar e o aprender, no contexto educacional, desde que sejam respeitadas as características do jogo como atividade espontânea, não produtiva e incerta". Estas características, que conciliam o jogar e o aprender, se colocam muitas vezes como uma ruptura com a forma de organização curricular tradicional, estabelecendo um contraponto às práticas conteudistas. 
Os jogos de representação (Roleplaying Games), conhecidos como RPG, são exemplos de jogos utilizados por educadores brasileiros desde a década de 1990 como ferramenta de motivação e desenvolvimento de conteúdos em espaços educacionais formais (RIYIS, 2017, p. 15). A utilização desse tipo de jogo em espaços educacionais se deve principalmente ao interesse dos docentes pelo jogo e à versatilidade que ele tem para a criação de práticas interdisciplinares (RIYIS, 2017, p. 39). O RPG é um jogo que além de utilizar tabuleiros para o desenrolar de seu enredo, pode ser encenado ao vivo (Live Action), o que o torna ainda mais lúdico e envolvente para os participantes (RIYIS, 2017, p. 35). Não obstante a isso, a revolução digital fez com que os jogos migrassem de espaços físicos, jogos de tabuleiro, para espaços digitais (BITTENCOURT; GIRAFFA, 2003). Essa é também uma tendência com jogos de RPG que estão ocupando esse novo espaço (AMARAL; SMITH, 2015).

Um jogo digital que tem uma grande penetração no público jovem é o Escape Room. É um jogo desenvolvido em equipe que tem como objetivo a realização de alguma tarefa com tempo determinado. Em geral, a tarefa é desvendar algum enigma para escapar de uma sala (GÓMEZ-URQUIZA et al., 2019). Adaptações desse jogo para espaços educacionais têm sido alvo de pesquisas recentes. As salas de Escape Room são montadas ludicamente para o desenvolvimento do jogo, e os resultados são bastante promissores com relação ao envolvimento das turmas e à motivação dos participantes. As pesquisas atuais mostraram a aplicabilidade desse jogo nas áreas de Matemática (CHARLO; DIOS, 2019), de Física (JAMBHERKAR; PAHLS; DELONEY, 2020), de Enfermagem (GÓMEZ-URQUIZA et al., 2019), de Farmácia (CAIN, 2019) e Médica (KINIO et al., 2019). Estes estudos foram desenvolvidos em um ambiente educacional de nível superior, investigando a taxa de sucesso dos participantes em escaparem das salas, o nível de satisfação dos alunos e os ganhos educacionais percebidos no processo. A grande versatilidade desse jogo despertou o interesse no desenvolvimento de uma Escape Room com o objetivo de trabalhar conteúdos de forma interdisciplinar no escopo do Curso Técnico em Eletroeletrônica integrado ao Ensino Médio.

As considerações apresentadas neste artigo são provenientes de um estudo qualitativo de natureza exploratória, conduzido por docentes das áreas de Eletroeletrônica, Administração, História e Informática. Trata-se da proposição e análise de uma Escape Room, cujos desafios foram propostos a partir da articulação de conteúdos e metodologias das referidas áreas, de forma interdisciplinar.

Vale ressaltar que trataremos aqui da etapa de criação do jogo, que ainda não passou por aplicação e validação junto a seu público-alvo. Pretende-se apresentar as dimensões teóricometodológicas que nortearam a elaboração da Escape Room, bem como sugerir, em caráter 
ainda preliminar, indicadores de ensino que possam contribuir para as próximas etapas de desenvolvimento do projeto. A Escape Room proposta neste artigo foi desenvolvida com a participação direta de um grupo de discentes, o que permitiu avaliar durante o processo criativo do jogo educativo, quais são os desafios mais motivadores e qual sequência de eventos envolve melhor os participantes.

O objetivo principal deste artigo é apresentar as etapas de criação de um jogo que seja de fácil reprodução em espaços educacionais formais, produzindo significados e criando ressignificações a conceitos que estão em construção nas turmas (BRUNER, 2002). Dessa forma, o artigo descreverá de forma pormenorizada todas as etapas necessárias para a criação do jogo. Até onde se tem conhecimento, uma descrição detalhada da montagem pedagógica de uma Escape Room no escopo do Ensino Técnico Integrado ao Ensino Médio é inédita na literatura nacional, não sendo muito diferente na literatura internacional.

Este artigo é organizado da seguinte forma: a presente seção apresentou a introdução do trabalho, seus objetivos e sua relevância. Na seção 2 é apresentada a estrutura básica para desenvolvimento de uma Escape Room. A estruturação para o desenvolvimento, a execução, os desafios e as significações do jogo específico proposto são apresentados na seção 3. Na seção 4 são realizadas as considerações finais do artigo.

\section{ESTRUTURA PARA O DESENVOLVIMENTO DO JOGO}

Para o desenvolvimento do jogo Escape Room é necessário definir algumas métricas que são próprias de sua concepção (SUNDSBO, 2019). Elas podem ser divididas em sete etapas de construção: (i) tema da Escape Room; (ii) a sala de fuga; (iii) tamanho do grupo; (iv) duração do jogo; (v) o mentor; (vi) os desafios e (vii) regras do jogo. Todo o enredo do jogo educativo deve ser pensado de forma a possibilitar que os participantes sejam estimulados e tenham ganhos educacionais no seu decorrer. As partes básicas do jogo são descritas a seguir:

- Tema da Escape Room. Parte inicial do desenvolvimento do jogo, em que se determina qual é o enredo, em que momento histórico se passa e quais elementos interdisciplinares serão discutidos. A participação dos alunos nesta etapa se mostra promissora, pois eles podem sugerir assuntos e discussões de interesse para a turma e que dialoguem mais efetivamente com o universo de sua faixa etária. Isso possibilitará ao docente conhecer melhor a turma e trabalhar os assuntos com o grupo, tanto no jogo quanto em outras situações.

ForScience, Formiga, v. 8, n. 2, e00851, jul./dez. 2020 
- A sala de fuga. A montagem física da sala de Escape Room deve retratar o ambiente e o tempo histórico em que se passa o jogo, harmonizando os elementos que fazem parte dos desafios com os elementos que não fazem. Esta parte tem como objetivo tornar o jogo lúdico e envolvente para os participantes. Cada objeto da sala deve estar contextualizado com o tema a ser discutido e todos os desafios propostos na sala devem ter ligação entre eles.

- Tamanho do grupo. A quantidade de participantes que devem entrar na Escape Room conjuntamente está relacionada com o tamanho da sala utilizada para o jogo, com o tempo de duração disponibilizado para a realização do jogo, com o nível de dificuldade dos desafios e com a necessidade de trabalho em equipe requerido.

- Duração do jogo. É o tempo disponibilizado para que os participantes possam desvendar os segredos da sala e escapar. Caso o tempo acabe, deverão sair da sala sem concluir os desafios propostos. Para a determinação desse tempo, o professor responsável deverá levar em consideração quanto tempo está disponível para a atividade (logística da escola) e se o tempo proposto é suficiente para a solução dos desafios presentes na sala. O tempo aqui indicado não se refere ao tempo necessário para o desenvolvimento das discussões inerentes ao jogo, mas somente à interação do grupo com a Escape Room.

- O mentor. A principal função do mentor do jogo é contextualizar os participantes na Escape Room, os situando no jogo e informando suas regras. Na maioria das vezes essa função é exercida pelo professor responsável. Além disso, compete ao mentor fornecer dicas previamente estabelecidas aos participantes quando solicitado. Em qualquer momento do jogo em que os participantes não conseguirem avançar em algum desafio eles poderão solicitar uma dica adicional ao mentor. Após o mentor proferir uma dica adicional, será descontado um tempo de penalidade aos jogadores. Esse tempo é arbitrado conforme o tempo de duração do jogo e da quantidade de desafios a serem desvendados. Assim, o tempo de penalidade deve ser ajustado conforme a necessidade das adaptações do jogo. A perda de tempo de resposta aos desafios também poderá ser substituída por outra restrição de funcionalidade, quando mais pertinente aos objetivos educacionais. 
- Os desafios. Os desafios propostos para a Escape Room devem ser desenvolvidos para possibilitar as discussões dos temas interdisciplinares que se deseja trabalhar. Pedagogicamente, os desafios devem mobilizar e articular conhecimentos prévios ou motivar a aprendizagem de conhecimentos novos. Esse tipo de metodologia favorece o processo de internalização do conhecimento conforme enunciado por Vygotsky (2003, p. 74): "chamamos de internalização a reconstrução interna de uma operação externa”.

- Regras do jogo. Os participantes têm um tempo máximo para escapar da sala. Não é permitido deslocar ou escalar móveis grandes presentes na sala. Não é permitido o uso de aparelhos celulares ou equipamentos afins durante o jogo. Os jogadores não podem forçar a abertura de portas, gavetas ou caixas que estejam trancadas. A abertura desses objetos só poderá ser realizada através do desvendamento dos enigmas da sala. O descumprimento de qualquer regra elimina o grupo do jogo.

\section{PROPOSTAS PARA A MONTAGEM DE UMA ESCAPE ROOM}

As três turmas do Ensino Técnico Integrado ao Ensino Médio que serviram de base para a proposta de Escape Room deste artigo têm em média 36 alunos. O jogo proposto tem duração de 30 minutos e seus desafios foram pensados para serem desvendados por grupos de quatro participantes. Um dos resultados apresentados em Gómez-Urquiza et al. (2019) mostra que dois terços dos grupos que entram na Escape Room conseguem escapar dela no tempo estipulado. Por ser um jogo educacional que tem por característica ser não produtivo e espontâneo em seu desenvolvimento (LIMA, 2008, p 13), o sucesso na aplicabilidade dele não está relacionado a todos os alunos conseguirem sair da sala no tempo estipulado, mas sim no envolvimento dos participantes ao longo do jogo e ao desenvolvimento das habilidades previstas pelos desafios. Para que toda a turma de 36 alunos participe é necessária a divisão em nove grupos e um tempo aproximado de cinco horas. Para turmas maiores ou uma disponibilidade de tempo menor, aconselha-se dividir a aplicação do jogo em dois ou mais momentos, dependendo da realidade da escola. Além do tempo necessário para a realização do jogo, os professores que desejam utilizar jogos em um ambiente de ensino formal, também devem dedicar tempo para explicar os motivos e os objetivos de sua aplicação. Isso se mostra fundamental, pois essa metodologia de ensino não é tradicionalmente utilizada em espaços formais de ensino (LIMA, 2008, p 14). Como mostrado por Kinio, Dufresne e Brandys (2018), somente 53,8\% dos alunos acham 
adequada a utilização de jogos, no caso investigado o jogo Escape Room, dentro da matriz curricular do curso. Assim, tradicionalmente os jogos são vistos meramente como uma atividade adicional na formação acadêmica. Para a mudança dessa percepção é necessário ressignificar o jogo nos espaços escolares para que ele seja entendido como mais uma metodologia de ensino que pode ser utilizada em diferentes propostas educativas.

Para cada dica dada pelo mentor do jogo serão descontados 5 minutos do tempo de duração, como penalidade. O tema do jogo e os desafios propostos estão detalhadamente descritos nas seções seguintes.

\subsection{Elaboração do tema do jogo}

A determinação do tema central da Escape Room norteará toda a construção do jogo, podendo ser arbitrado pelo professor ou ser escolhido pela turma. Para a proposição do tema central do jogo pedagógico proposto neste artigo optou-se por contar com a ajuda da turma. Para isso, foram escolhidos cinco alunos do primeiro ano do Curso Técnico em Eletroeletrônica Integrado ao Ensino Médio do IFMG Campus Ribeirão das Neves. A escolha dos participantes para a elaboração do tema balizou-se na disponibilidade e interesse dos alunos em participar do desenvolvimento da proposta pedagógica. Considerando-se o caráter exploratório do trabalho, optou-se por limitar o número de estudantes (cinco) e docentes (três) envolvidos inicialmente na proposta, otimizando-se as trocas entre o grupo. $\mathrm{O}$ envolvimento dos alunos e dos professores nesta parte do projeto se deu de forma voluntária e espontânea. Esse tipo de participação é um limitante nas análises quantitativas dos resultados, como apresentado em Gómez-Urquiza et al. (2019), já que que não traz um indicativo da comunidade acadêmica como um todo, mas sim de um recorte da mesma. Entretanto, a riqueza da construção coletiva do jogo mostra-se como um processo pedagógico enriquecedor, posto que neste momento de escuta e ação é possível dar fala aos alunos e entender quais os assuntos eles visualizam como tema central para o desenvolvimento do jogo. Entende-se que a participação dos alunos na escolha do tema é uma forma de demonstrar "o respeito à autonomia e à dignidade de cada um" (FREIRE, 2011, p. 58). Ao professor compete realizar a articulação dos assuntos que surgem durante a discussão, visando estruturar o conhecimento de forma lógica e sequencial.

Na parte de proposição do tema da Escape Room diversos momentos históricos foram elencados como pano de fundo para o jogo. Para cada momento histórico discutido se apresentaram textos de referência para os alunos e para os professores envolvidos, o que possibilitou o aumento do conhecimento do grupo em relação aos recortes históricos estudados. 
Ao final de cada texto lido, os integrantes socializaram suas impressões e opiniões e na sequência, buscava-se uma síntese no grupo por meio de debates. Diversos momentos históricos foram debatidos em grupos, como exemplo, a Guerra de Secessão Americana, a Era Dourada dos Estados Unidos da América (EUA), a Primeira Guerra Mundial, a Segunda Guerra Mundial e o Brasil no século XXI. A cada recorte histórico foram feitas discussões sobre o desenvolvimento tecnológico da época e as relações perceptíveis entre ciência, ética, participação feminina e poder econômico.

O momento histórico escolhido para o desenvolvimento da Escape Room foi o período compreendido entre os anos de 1939 e 1945. Decidiu-se, portanto, considerar a Segunda Guerra Mundial como pano de fundo para o desenvolvimento do jogo pedagógico (HOBSBAWM, 2008). Alguns eixos interdisciplinares mostraram-se fundamentais para a elaboração dos desafios: (i) a geopolítica mundial da época; (ii) as relações interpessoais durante a guerra; (iii) o papel das mídias e das propagandas e (iv) os avanços tecnológicos e seus impactos na sociedade. Ao longo dessa seção são apresentados assuntos específicos a serem trabalhados em função de cada desafio do jogo.

A Segunda Guerra Mundial está inserida em um momento histórico intitulado como "A Era dos Extremos" por Hobsbawm (2008). Escolhido o pano de fundo para a Escape Room, realizou-se um recorte histórico e geopolítico para a montagem dos desafios da sala. Assim, decidiu-se que o jogo se passaria em Varsóvia, Polônia, no ano de 1942. A sala da qual os participantes terão que escapar é um escritório de fachada montado por um grupo da resistência polonesa contra a ocupação nazista. Nesse escritório atua um grupo que tem autorização do gabinete sanitário nazista para adentrar no gueto de Varsóvia, onde estima-se que o governo alemão concentrou, simultaneamente, mais de 400 mil judeus em uma área de cerca de 3,3 quilômetros quadrados (HOLOCAUST FORGOTTEN, 2020). Essa autorização é devida à atuação do grupo no controle de epidemias. Uma integrante desse grupo é Irena Sendler (HOLOCAST FORGOTTEN, 2020) cuja missão principal é o resgate de crianças do gueto. Os participantes do jogo são convidados a trabalhar neste escritório sanitário e ao desvendarem os desafios da sala poderão fazer parte dessa história. A especificação da sala permite personalizar o jogo e orientar as discussões.

\subsection{Os desafios do jogo}

Os desafios construídos em consonância com o tema do jogo visam possibilitar discussões interdisciplinares em turmas de ensino médio e técnico, sendo apresentadas 
possibilidades para adequações em outras situações. Estes desafios têm como característica estimular o empenho dos participantes na solução dos problemas trazidos por eles. Clain (2019) destaca em seu trabalho que para 91\%, dos 141 alunos do curso de farmácia que participaram da pesquisa, o engajamento e a motivação são maiores para solucionar os desafios da Escape Room que para solucionar os problemas que são tipicamente apresentados em sala de aula.

\subsubsection{A carta de acolhida}

Após a realização da contextualização e da apresentação das informações iniciais pronunciadas pelo mentor do jogo, os participantes iniciam sua jornada pela Escape Room, cujo cenário deverá estar montado em formato de uma sala de escritório, recebendo as introduções dispostas na carta de acolhida que é apresentada na Figura 1. Inicialmente, somente aparecerá a mensagem da parte superior da figura. A mensagem em negrito somente se revelará quando exposta à luz negra. Os participantes deverão ler atentamente a carta para retirar dela as primeiras instruções. O primeiro parágrafo da carta traz uma visão geral de onde os jogadores se encontram. O segundo parágrafo indica aos jogadores o motivo porque eles estão trancados na sala, ao passo que o terceiro parágrafo traz as primeiras instruções do jogo e a exortação de que eles deverão encontrar a forma de deixar o local.

As atividades de ensino que serão realizadas ao final do jogo que têm como base a carta de acolhida são: (i) discussão sobre focos de tensão na Europa durante a Segunda Guerra Mundial; (ii) a invasão da Polônia; (iii) saneamento básico para contenção de doenças e (iv) prevenção e tratamento de doenças infecciosas bacterianas e virais.

A primeira instrução dada aos jogadores no terceiro parágrafo é que eles devem se dirigir ao local de trabalho. A primeira dica do jogo deve fazer com que os jogadores se encaminhem à mesa presente na sala, posto que este é o local tradicional de realização de trabalhos administrativos. Na mesa de trabalho, o segundo desafio do jogo é os participantes ligarem a luz negra sobre a folha de instruções (dica dada em "Cuidado para a luminosidade não atrapalhar suas tarefas"). A lâmpada que fornecerá a luz negra estará dentro de um abajur posicional em cima da mesa de trabalho. Ao ligarem a lâmpada um texto escrito com "caneta invisível” aparecerá conforme texto em negrito da Figura 1, dando novas instruções para os jogadores. Ao término do jogo deverá ser perguntado aos participantes por que a mensagem somente apareceu após ligada a luz? Assim, será possível realizar discussões físicas sobre fontes de emissão de raios ultravioleta, a frequência, o período e o comprimento de onda destes sinais. 


\begin{abstract}
Prezados,
Desculpe não recebê-los em seu primeiro dia de trabalho neste departamento de controle sanzitário. Rumores de que mortess ocorrem no gueto de Varsóvia devido ao Tifo, fineriam com que todá a equipe fosse deslociada pará lá.

Informo que ao deixar o escritório, eu tranquei a porta para a segurança de vocês. Os tempos são dificeis a muitos grupos estão em confronto na cidade.

Dirijam-se ao seu local de trabalho e năo percam tempo. Cuidado pará a luminosidade não atrapalhar suas tarefás. Quando encontrarem a chave venham nos encontrar no gueto de Varsóvia.

Atenciosamente,

Irená Sendler
\end{abstract}

A mensagem em negrito somente aparecerá quando a folha for exposta a luz negra

Observe as coordenadas deste local.

O segredo é errar na escolha do número inteiro da raiz do produto!

\title{
LMJ7PM9D LJM DIAJMH7J9N 9 I5J 9I7JIOM9D \\ 6PNLP9D LJM A5OJN 9 H9 AJD DIPODG \\ 9N7PO5M9D 5BJM5 J JPOMJ G58J \\ ODM5M9D HDIC5N LMJLMD5N 7JI7GPNJ9N
}

Figura 1- Carta de acolhida com instruções aos participantes do jogo

Fonte: Autores (2020).

\subsubsection{O decodificar de Júlio Cesar}

O desafio que se revela no texto em negrito apresentado na Figura 1 é composto de duas partes: um texto inteligível e um texto codificado. O texto inteligível apresenta informações para os jogadores poderem decodificar o texto codificado. A primeira frase informa para os participantes do jogo observarem "as coordenadas deste local". Como os participantes já foram contextualizados no primeiro parágrafo da carta do local onde se encontram, eles devem deduzir que as coordenadas solicitadas são as coordenadas geográficas de Varsóvia, Polônia. Para conseguirem essa informação, os participantes deverão encontrar o mapa presente na sala. Nesse mapa eles deverão identificar as coordenadas geográficas de Varsóvia, Polônia: latitude $50^{\circ}$ Norte e longitude $20^{\circ}$ leste. As coordenadas aproximadas de Varsóvia servem de referência para a próxima etapa desse desafio.

A próxima etapa indica que "O segredo é errar na escolha do número inteiro da raiz do produto!”. Os jogadores deverão inferir que as coordenadas geográficas encontradas servem de 
base para as operações matemáticas listadas na frase. Assim, eles serão capazes de fazer as seguintes operações: primeiro, o produto das coordenadas, 50 × $20=1.000$; segundo, a raiz quadrada do produto, que vale aproximadamente 31,62 ; e por fim, deverão errar no arredondamento do número inteiro, ou seja, considerar o número 31 e não o 32, que seria o correto de acordo com as regras de arredondamento.

As discussões de ensino relacionadas com essas atividades são: (i) coordenadas geográficas; (ii) cartografia; (iii) operações matemáticas básicas: multiplicação, potenciação e radiciação e (iv) arredondamento e algarismos significativos.

O resultado da operação matemática é o segredo para decodificar a mensagem utilizando o processo baseado na metodologia utilizada pelo imperador romano Júlio César. Essa codificação é basicamente a utilização de um alfabeto deslocado para o envio de mensagens, ou seja, escreve-se uma mensagem e descola-se cada letra da mensagem uma quantidade específica de letras. Como exemplo, a mensagem "Sucesso a todos" deslocada três letras à frente gera a mensagem criptografada "VXFHVVR D WRGWV". Esse tipo de codificação é facilmente decodificado, utilizando o alfabeto devidamente deslocado, conforme Figura 2.

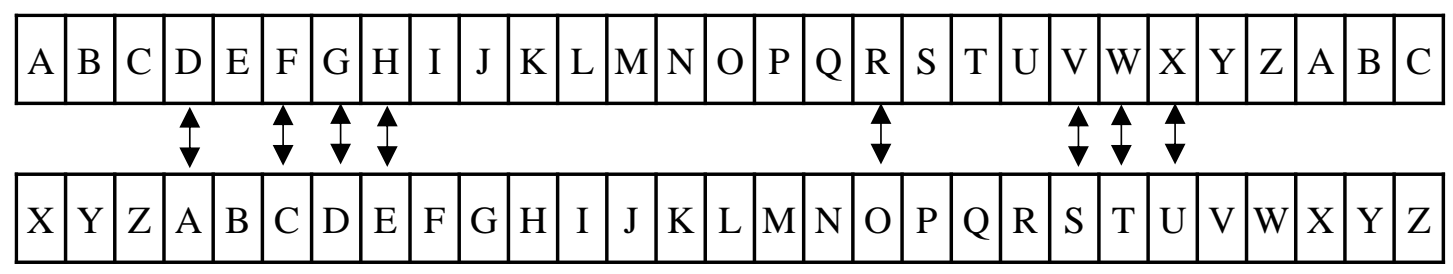

Figura 2- Processo de codificação/decodificação baseado na metodologia de Júlio Cesar Fonte: Autores (2020).

Para decodificação da mensagem em negrito da Figura 1, ficará disposto na sala uma roda de cifras de César, Figura 3, que os jogadores deverão utilizar para descobrir qual é a mensagem codificada. Rodando o círculo interno da roda de cifras por 31 posições a mensagem codificada "LMJ7PM9D LJM DIAJMH7J9N 9 I5J 9I7JIOM9D / 6PNLP9D LJM A5OJN 9 H9 AJD DIPODG / 9N7PO5M9D 5BJM5 J JPOMJ G58J / ODM5M9D HDIC5N LMJLMD5N 7JI7GPNJ9N" pode ser decodificada. Depois de movimentadas as posições, deve-se inserir a mensagem codificada no círculo externo e ler a mensagem decodificada "Procurei por informações e não encontrei / Busquei por fatos e me foi inútil / Escutarei agora o outro lado/Tirarei minhas próprias conclusões" no círculo interno.

O processo de decodificação apresentado no jogo serve de base para a discussão de processos de codificação mais elaborados que são apresentados em ementas de cursos técnicos, como o código BCD 8421, o código Excesso de 3, o código Gray, o código de 5 bits, o código 
9876543210 e outros códigos BCD de 4 bits (CAPUANO; IDEOTA, 2019, p. 179-184). Caso o jogo seja aplicado a uma turma do ensino médio convencional essa discussão pode ser suprimida.

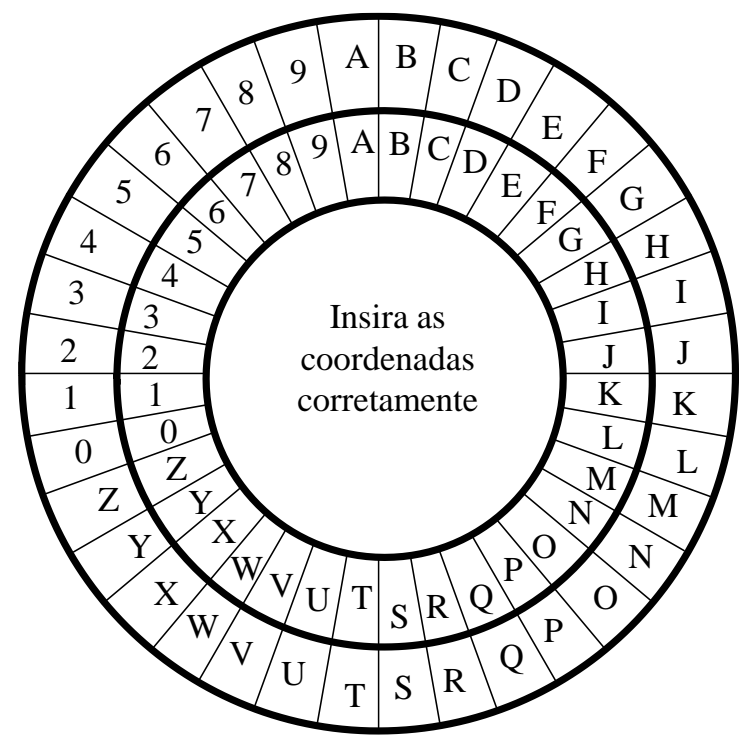

Figura 3 - Cifras de Júlio Cesar Fonte: Autores (2020).

\subsubsection{A sintonia do rádio}

Concluída a decodificação da mensagem, os jogadores terão pistas para o próximo passo do jogo nessa mensagem. Na Escape Room terá um rádio funcionando durante todo o jogo. Esse rádio estará tocando músicas de Richard Wagner, apreciadas por Joseph Goebbels, ministro da propaganda na Alemanha nazista. Observação importante sobre o jogo, a sintonia inicial do rádio deverá ser 3 - Reproduza, 5 - Nosso(a)s e 5 - Ideias, conforme Figura 4. Isso possibilitará discussões sobre guerra psicológica e disseminação de informações manipuladas, conhecidas como (Fake) News (DEMO, 2000).

A dica dada na mensagem "Escutarei agora o outro lado" deve levar os jogadores em direção ao rádio. Embaixo do rádio estará disposta uma tabela para sintonizar as estações, conforme mostra a Figura 4. A frequência de sintonia é realizada por meio de três botões. Para encontrar a frequência correta, os jogadores deverão utilizar a mensagem "Tirarei minhas próprias conclusões”. Inserindo está mensagem na tabela de sintonia do rádio é possível sintonizar a emissora de interesse que reproduzirá uma mensagem com as próximas dicas.

Todas as emissoras de rádio deverão estar transmitindo alguma mensagem. Em síntese todas as emissoras poderão executar mensagens padrão com o mesmo início ou músicas da época. O início de todas as mensagens deverá ser: "Em (....ruído...), 15h30min. Boa tarde. 
Escutem o noticiário até o final. Nos Países Baixos, relata-se que nos territórios ocupados pela Alemanha iniciou-se a deportação da comunidade judaica para campos de trabalho situados no leste europeu. A rádio de Berlim descreveu a ação como uma forma de reassentamento dos judeus. Nosso correspondente de guerra traz mais informações sobre o caso: "Uma movimentação diferente começou a ser observada pela cidade, a Gestapo tem intensificado os esforços para identificação dos judeus nos Países Baixos, aumentando o clima de incerteza no país". Do outro lado do Atlântico, o Brasil assinou a Carta do Atlântico e passou a ser considerado não neutro no conflito global pela Alemanha". Para diversificar, essa mesma mensagem poderá ser reproduzida em diversos idiomas além do português, como exemplo o espanhol e o inglês.

\begin{tabular}{|c|c|c|}
\hline Botão I & Botão II & Botão III \\
\hline 0 Consolide & 0 Quaisquer & 0 Ilusões \\
\hline 1 Obtenha & $1 \mathrm{Um}(\mathrm{a}) \mathrm{s}$ & 1 Análises \\
\hline 2 Escute & 2 Suas/seus & 2 Fatos \\
\hline 3 Reproduza & 3 Velho(a)s & 3 Mitos \\
\hline 4 Modifique & 4 Novo(a)s & 4 Sínteses \\
\hline 5 Tire & 5 Nosso(a)s & 5 Ideias \\
\hline 6 Ouça & 6 as/os & 6 Esperanças \\
\hline 7 Crie & 7 Algum(a)s & 7 Conclusões \\
\hline 8 Busque & 8 Vário(a)s & 8 Mentiras \\
\hline 9 Repita & 9 Certo(a)s & 9 Utopias \\
\hline
\end{tabular}

Figura 4 - Sintonizador do rádio Fonte: Autores (2020).

Na sintonia correta indicada pela Tabela, 5 - Tire, 2 - Suas/seus e 7 - Conclusões, após a mensagem padrão será reproduzida a mensagem: "Para quem encontra-se trancado no escritório, é importante que se saiba que o grupo que aqui trabalha resgatou do gueto de Varsóvia um total aproximado de 3.000 judeus, sendo que a metade do número de crianças resgatadas excede o dobro do número de adultos resgatados em 250 . Utilize a quantidade de adultos resgatados para abrir a caixa." Essa caixa está trancada por um cadeado com segredo, cuja senha é o número de adultos resgatados. Dentro da caixa, encontra-se a chave para destrancar a porta e sair da sala.

Os desafios presentes na sintonia do rádio possibilitam discussões sobre circuitos ressonantes, marketing, mídia, revolução cultural e pronomes relativos. Além disso, com a mensagem do rádio é possível discutir operações matemáticas envolvendo equações lineares e 
leitura de problemas. O tópico de circuitos ressonantes é específico de cursos técnicos da área de eletrotécnica, eletrônica ou eletroeletrônica. Para a situação em que o jogo seja aplicado em turma do Ensino Médio convencional, esse tópico pode ser suprimido.

\section{CONSIDERAÇÕES FINAIS}

Este trabalho apresenta e discute as fases de construção de um jogo conhecido como Escape Room para ser executado em turmas do Curso Técnico em Eletroeletrônica Integrado ao Ensino Médio. Esse jogo educativo apresenta a possibilidade de ser adaptado e utilizado em turmas do Ensino Médio convencional da rede de educação privada e das redes federal, estaduais e municipais de ensino. Os desafios que compõem o jogo buscam identificar quais competências ainda não foram desenvolvidas pelos estudantes, introduzir temáticas interdisciplinares e motivar os alunos a buscar por novos conhecimentos. É necessário entender ainda que este e outros jogos aplicados na educação não têm como objetivo substituir o trabalho do professor ou romper com as metodologias de ensino tradicionais, mas surgem como metodologias que têm muito a contribuir para o trabalho docente e a melhorar o processo de ensino e aprendizagem pois por meio deles, o professor pode trabalhar de diferentes formas durante a condução da disciplina.

Os desafios propostos para a composição da Escape Room servem para a motivação na apresentação de novos conteúdos e para o diagnóstico da efetividade de conteúdos lecionados anteriormente ao jogo. Como mostrado na seção 3, as possibilidades de aprendizagem por meio do jogo proposto podem ser inúmeras, assim como a ampla variedade de temas interdisciplinares que podem ser trabalhados. A abrangência dos assuntos listados mostra o amplo alcance que o jogo pode ter, facilitando o trabalho do professor como mediador de assuntos transversais e tornando o processo de ensino e aprendizado mais contextualizado e interessante para os discentes.

Na continuação dessa pesquisa será empregado o jogo proposto neste artigo em turmas do Curso Técnico Integrado em Eletroeletrônica do IFMG campus Ribeirão das Neves. Assim, será investigado de forma minuciosa quais os níveis de satisfação das turmas com a participação no jogo e quais os ganhos educacionais foram alcançados. 


\section{REFERÊNCIAS}

AMARAL, R., SMITH, P. RPG Digital para o Ensino de Física. In: SIMPÓSIO HIPERTEXTO E TECNOLOGIAS NA EDUCAÇÃO $2^{\circ}$ COLÓQUIO INTERNACIONAL DE ECUCAÇÃO COM TECNOLOGIA., $6^{\circ}$, 2015. Pernambuco. Anais... UFPE: Pernambuco, 2015. p. 1-22, 2015.

BITTENCOURT, J. R., GIRAFFA, L. M. M. Role-playing games: a utilização do roleplaying games digitais no processo de ensino-aprendizagem. 2003. 62 p. Dissertação (Mestrado em Ciência da Computação) - Pontifícia Universidade Católica do Rio Grande do Sul, Porto Alegre, 2003.

BACICH, L., MORAN, J. Metodologias ativas para uma educação inovadora. Porto Alegre: Penso, 2018.

BORBA, M. C., PENTEADO, M. G. Informática e educação matemática. Belo Horizonte: Autêntica, 2001.

BRUNER, J. Atos de significação. Porto Alegre: Artes Médicas, 1997.

CAIN, J. Exploratory implementation of a blended format Escape Room in a large enrollment pharmacy management class. Currents in Pharmacy Teaching and Learning, v. 11, n. 1, p. 44-50, jan. 2019.

CAPUANO, F. G., IDEOTA, I. V. Elementos de eletrônica digital. 42. ed. São Paulo: Érica, 2019.

CHARLO, J. C. P., DIOS, M. T. C. Escape Room y aprendizaje mixto como herramientas para la formación de maestros de educación primaria. Brazilian Journal of Development, v. 5, n. 6, p. 5983-5992, jun. 2019.

DEMO, P. Ambivalências da sociedade da informação. Ciência da Informação, Brasília, v. 29, n. 2, p. 37-42, maio/ago. 2000.

FIALHO, W. C. G., MENDONÇA, S. O Pisa como indicador de aprendizagem de ciências. Roteiro, Joaçaba, v. 45, n. 1, p. 1-24, fev. 2020.

FREINET, C. A educação pelo trabalho. Lisboa: Editorial Presença, 1960.

FREIRE, P. Pedagogia da autonomia: saberes necessários à prática educativa. São Paulo: Paz e Terra, 2011.

FREIRE, P. Pedagogia do oprimido. Rio de Janeiro: Paz e Terra, 2013.

FOGARTY, R. Problem-based learning: a collection of articles. Arlington Heights: Skylight, 1998. 
GÓMEZ-URQUIZA, J. L. et al. The Impact on nursing students' opinions and motivation of using a "nursing Escape Room" as a teaching game: a descriptive study. Nurce Education Today, v. 72, n. 1, p. 73-76, jan. 2019.

HOBSBAWM, E. A Era dos extremos. São Paulo: Companhia das Letras, 2008.

HOLOCAUST FORGOTTEN. Irena Sendler: holocaust heroine. Disponível em: http://www.holocaustforgotten.com/sendler.htm. Acesso em: 07/04/2020.

HUIZINGA, J. Homo ludens: o jogo como elemento da cultura. 4. ed. São Paulo: Perspectiva, 1996.

KOLB, A. Y., KOLB, D. A. Learning styles and learning spaces: enhancing experimental learning in higher education. Academy of Management Learning \& Education, v. 4, n. 2, p. 193-212, jun. 2005.

JAMBHERKAR, K., PAHLS, R. P., DELONEY, L. A. Benefits of an Escape Room as a novel educational activity for radiology residents. Academic Radiology, v. 27, n. 2, p. 276283, fev. 2020.

JAPIASSU, H. Interdisciplinaridade e patologia do saber. Rio de Janeiro: Imago, 1976.

KINIO, A. E., DUFRESNE, L., BRANDYS, T. Break out of the Classroom: the use of Escape Rooms as an alternative teaching strategy in surgical education. Journal of Surgical Education, v. 76, n. 1, p. 134-139, 2018.

KINIO, A. E. et al. Break out of the classroom: the use of Escape Rooms as an alternative teaching strategy in surgical education. Journal of Surgical Education, v. 76, n. 1, p. 134139, jan. 2019.

KOLB, A. Y.; KOLB, D. A. Learning styles and learning spaces: enhancing experiential learning in higher education. Academy of Massachusetts Learning \& Education, v. 4, n. 2, p. 193-212, 2005.

LIMA, J. M. O jogo como recurso pedagógico no contexto educacional. São Paulo: Cultura Acadêmica: Universidade Estadual Paulista, Pró-Reitoria de Graduação, 2008.

OLIVEIRA, P. C., OLIVEIRA, C. G. Using conceptual questions to promote motivation and learning in physics lectures. European Journal of Engineering Education, v. 38, n. 4, p. 417-424, 2013.

RIYIS, M. T. Simples - Sistema inicial para mestres - professores lecionarem através de uma estratégia motivadora: um manual prático para o uso dos jogos cooperativos de representação e RPG na educação. São Paulo: Jogo de Aprender, julho, 2017.

ROMANATTO, M. C. Resolução de problemas nas aulas de matemática. Revista Eletrônica de Educação, v. 6, n. 1, p. 299-311, maio 2012.

SCHMECK, R. Learning strategies and learning Styles. New York: Plenum Press, 1988. 
SUNDSBO, K. Open access Escape Room: instructions, Jan. 2019.

TORI, R. Educação sem distância: as tecnologias interativas na redução de distâncias em ensino e aprendizagem. São Paulo: Senac, 2010.

VYGOTSKY, L. S. A formação social da mente: o desenvolvimento dos processos psicológicos superiores. São Paulo: Martins Fontes, 2003.

\section{DADOS DOS AUTORES}

Nome: Guilherme da Silva Lima

E-mail: guilherme.silva@ifmg.edu.br

Curriculum Lattes: http://lattes.cnpq.br/1265413459106186

Graduado (2011) em engenharia elétrica pelo Centro Federal de Educação Tecnológica de Minas Gerais (CEFET-MG), mestrado (2015) e doutorado (2020) em engenharia elétrica pela Universidade Federal de Minas Gerais (UFMG). Possui especialização em docência na educação profissional (2020) pelo Instituto Federal de Educação, Ciência e Tecnologia de Minas Gerais (IFMG). Desde 2016 é professor do Instituto Federal de Minas Gerais (IFMG). Desde de 2017 é coordenador do curso técnico em eletroeletrônica integrado ao ensino médio do IFMG campus Ribeirão das Neves. As pesquisas de interesse estão relacionadas à modelagem de linhas de transmissão, ensaios laboratoriais de alta tensão, fenômenos associados a descargas atmosféricas e aterramentos elétricos. Além do interesse por pesquisas na área de educação tecnológica.

Nome: Ederson dos Santos Ramalho

E-mail: ederson.ramalho@ifmg.edu.br

Curriculum Lattes: http://lattes.cnpq.br/6724048824104332

Mestrado em Ciências Contábeis pela Fundação Visconde de Cairu Salvador; especialização e graduação em Ciências Contábeis pela Pontifícia Universidade Católica/MG. Coordenou cursos de graduação na IES Centro Universitário Una: Ciências Contábeis, Administração de Empresas e Ciências Econômicas. Atualmente, é professor efetivo do IFMG Campus Ribeirão das Neves. Tem experiência nas áreas de Administração e Contabilidade. Atua principalmente nas seguintes áreas de pesquisa: Educação, Controladoria, Avaliação de Empresas, Administração Financeira e Orçamentária, Contabilidade Pública, Gestão Estratégica de Custos.

Nome: Juliana Ventura de Souza Fernandes

E-mail: juliana.fernandes@ifmg.edu.br

Curriculum Lattes: http://lattes.cnpq.br/4777162566366921

Doutoranda e mestrado em História pela Universidade de Minas Gerais; e, graduação em História pela Universidade Federal de Ouro Preto e em Psicologia pela Universidade Federal de São Carlos. Foi contemplada com bolsa da Fundação Santander para a realização de Curso de Língua Espanhola e disciplinas na Universidad de La Rioja, Espanha e com bolsa da Redmacro (Red de Macrouniversidades de América Latina e Caribe) para mobilidade acadêmica na Universidad Nacional Autonoma de México no doutorado. Atualmente, é professora do Ensino Básico, Técnico e Tecnológico do Instituto Federal de Minas Gerais Campus Ribeirão das Neves. 
Nome: Edio da Costa Junior

E-mail: edio.junior@ifmg.edu.br

Curriculum Lattes: http://lattes.cnpq.br/3940873823396403

Doutorado e mestrado em Geofísica Espacial do Instituto Nacional de Pesquisas Espaciais na linha Física de Plasmas Espaciais/Magnetosfera e Heliosfera; e, graduação em Física (Bacharelado e Licenciatura) pela Universidade Federal de Viçosa. Atualmente é professor do Instituto Federal de Educação, Ciência e Tecnologia de Minas Gerais - Campus Ouro Pedro Foi coordenador do Curso de Licenciatura em Física e chefe da área de Física do IFMG - Ouro Preto entre janeiro de 2015 e outubro de 2019 e, é coordenador de área de Física do PIBID desde agosto de 2018. 